\section{WHAT IS THE REALITY? THE SURGEON VERSUS THE CARDIOLOGIST DEPLOYMENT INSUFFICINECIES IN TAVI PROCEDURES: PARAVALVULAR LEAK, ANNULAR RUPTURE, AND PACEMAKER NEED Reply to the Editor:}

In addition to the operative complications and adverse effects, the main disadvantages of aortic prostheses used in open surgery are the mandatory use of warfarin in mechanical heart valves and the sewing cuff, which prevents the use of larger prostheses for implantation and causes a potential patientprosthesis mismatch. These factors have impelled surgeons and researchers to find a better prosthesis. To avoid warfarin, bioprosthetic heart valves were introduced; to implant larger prostheses, new prostheses with minimal sewing cuffs were designed; to reduce surgery-related adverse effects, minimally invasive approaches (MIAs), including transfemoral or transapical valve implantation, were introduced. None of these developments, however, could have completely solved the problems of aortic valve replacement procedures.

Although a biocompatible leaflet has been constructed in the light of new technologic developments, it is still not as near to perfect as desired. It is evident that MIAs may decrease complication rates or adverse surgical events, as also mentioned by Dohmen and colleagues ${ }^{1}$ : MIAs may reduce ventilation time, decrease incisional pain, reduce wound infections, reduce blood loss and transfusions, and decrease the time to discharge. More importantly, MIAs have significantly reduced mortality and morbidity. We all agree with these statements; however the quality of work performed in the treatment of valve dysfunction during the conventional open surgical approach cannot be sacrificed for reductions in ventilation time, wound infections, blood loss, and other parameters. In other words, the beneficial effects of MIAs are only acceptable if the quality of work obtained is comparable with that of open surgical approaches. If the quality of work obtained during the MIA does not meet the success obtained during open surgery in terms of valvular function, something may have gone wrong while designing the sutureless prosthesis.

The sutureless bioprosthesis used in MIAs may give the impression that it has somewhat solved the problems; when the sutureless prosthesis is scrutinized, however, some insufficiencies of the design may be determined. ${ }^{2}$ The first insufficiency is the necessary force for dilatation, which was reported as $3 \mathrm{~atm}(2280 \mathrm{~mm} \mathrm{Hg})$ and 4 atm $(3040 \mathrm{~mm} \mathrm{Hg})$ by Flameng and associates $^{3}$ and Minh and colleagues, ${ }^{4}$ respectively. The effects of the force on the annulus are permanent, because the acquired shape of the prosthesis is constant. This approach may cause annular rupture, which was possibly the cause of life-threatening bleeding, reported at $4.2 \%$, or the need for permanent pacemaker for complete block, reported at $9 \%$ by Babaliaros and coworkers. ${ }^{5}$ Although the complication rates have not been specifically mentioned by Dr Dohmen, in a metaanalysis of 8874 patients treated with transcatheter aortic valve implantation (TAVI), the life-threatening major bleeding and pacemaker implantation rates were $13.8 \%(\mathrm{n}=1224)$ and $12.5 \%(\mathrm{n}=1106)$, respectively. ${ }^{6}$

The second insufficiency is that larger prosthesis size preference for tight settlement of the prosthesis is mandatory; for example if you prefer to use a CoreValve prosthesis, you must use 23-mm, 26-mm, 29-mm, and 31-mm prostheses for annuli with diameters of 18 to $20 \mathrm{~mm}, 20$ to $23 \mathrm{~mm}, 23$ to $26 \mathrm{~mm}$, and 26 to $29 \mathrm{~mm}$, respectively. With larger prostheses, the force of the dilatation may therefore result in annular rupture or permanent atrioventricular block. The third insufficiency is paraprosthetic leak, which probably occurs as a result of unsatisfactory dilatation of sutureless prostheses, especially in the early postprocedural period. We may speculate that forceful dilatation performed during the deployment according to the manufacturer's instructions may result in annular rupture or permanent $\mathrm{AV}$ block, whereas dilatation lower than manufacturer's instructions or preference for a prosthesis equal in size to the aortic annulus (rather than a larger one) may cause loose (rather than tight) implantation of prosthesis, which is probably the cause of early and late paravalvular leak, reported at $8.8 \%{ }^{5}$

In conclusion, aortic stenosis is the most common valvular heart disease in adults. ${ }^{7}$ It is becoming more frequent as the age of the population increases. It was reported that almost one-third of patients older than 75 years with severe aortic stenosis do not undergo conventional aortic valve replacement because of risks related to advanced age and comorbidities. These findings have stimulated surgeons, cardiologists, and manufacturers to develop a lessinvasive aortic valve replacement procedure. During the introduction of this new approach, as a result of insufficient reports of complications related to the procedure, some procedural insufficiencies designated as "learning curve" arise. Although the possible complications and adverse effects of transcatheter aortic valve implantation procedures have been well described and documented in the systematic review by Yan and colleagues, ${ }^{8}$ many reports of the same deployment technique and same construction properties of prosthesis (the necessity of a larger valve size for a smaller annulus) advocate the superiority of transaortic or transapical approaches. The complications, including life-threatening bleeding, the need for permanent pacemaker implantation, and paraprosthetic leak, are not related to the preferred approach; rather, those insufficiencies are related to the deployment strategy and prosthesis design.

Murat Tavlasoglu, $M D^{a}$

A. Baris Durukan, $M D^{b}$

${ }^{a}$ Department of Cardiovascular Surgery 
Gulhane Military Medical Academy

Ankara, Turkey

${ }^{b}$ Department of Cardiovascular

Surgery

Memorial Ankara Hospital

Ankara, Turkey

\section{References}

1. Dohmen PM, Misfeld M, Borger MA, Mohr FW. Current trends in aortic valve replacement: development of the rapid deployment aortic valve replacement with the EDWARDS INTUITY valve system. Expert Rev Med Devices. 2013;10:461-70.

2. Tavlasoglu M, Guler A, Yesil FG. Should sutureless aortic valve replacement be preferred only for decreasing aortic crossclamp time? J Thorac Cardiovasc Surg. 2014;147:1726-7.

3. Flameng W, Herregods MC, Hermans H, Van der Mieren G, Vercalsteren M, Poortmans G, et al. Effect of sutureless implantation of the Perceval $S$ aortic valve bioprosthesis on intraoperative and early postoperative outcomes. J Thorac Cardiovasc Surg. 2011;142:1453-7.

4. Minh TH, Mazine A, Bouhout I, El-Hamamsy I, Carrier M, Bouchard D, et al. Expanding the indication for sutureless aortic valve replacement to patients with mitral disease. J Thorac Cardiovasc Surg. 2014;148:1354-9

5. Babaliaros V, Devireddy C, Lerakis S, Leonardi R, Iturra SA, Mavromatis K, et al. Comparison of transfemoral transcatheter aortic valve replacement performed in the catheterization laboratory (minimalist approach) versus hybrid operating room (standard approach): outcomes and cost analysis. JACC Cardiovasc Interv. 2014;7:898-904.

6. Giordana F, D'Ascenzo F, Nijhoff F, Moretti C, D’Amico M, Biondi Zoccai G, et al. Meta-analysis of predictors of all-cause mortality after transcatheter aortic valve implantation. Am J Cardiol. 2014; 114:1447-55

7. Iung B, Baron G, Butchart EG, Delahaye F, Gohlke-Bärwolf C, Levang OW, et al. A prospective survey of patients with valvular heart disease in Europe: the Euro Heart Survey on Valvular Heart Disease. Eur Heart J. 2003;24:1231-43.

8. Yan TD, Cao C, Martens-Nielsen J, Padang R, $\mathrm{Ng}$ M, Vallely MP, et al. Transcatheter aortic valve implantation for high-risk patients with severe aortic stenosis: a systematic review. J Thorac Cardiovasc Surg. 2010;139:1519-28.

http://dx.doi.org/10.1016/

j.jtcvs.2014.09.130

\section{WE HAVE TO BE PIONEERS: WE OWE IT TO THE FUTURE GENERATIONS}

To the Editor:

...Each is given a bag of tools,/ A shapeless mass,/A book of rules;/ And each must make-l Ere life is flown-/A stumbling block/Or a stepping stone.
It was 1997 when I started my experience in cardiac surgery. It was a new world to my eyes, and I could hardly remain indifferent to the magic behind cardiac surgery.

I was consumed by the pleasure of reading about pioneers of the 1950s. Only nowadays I really understand their efforts in giving us the opportunity to operate on children who were previously destined to die. They were doctors, scientists, and engineers at the same time. I still strongly have in my mind the image of the first open-heart surgical operation: a grainy blackand-white photograph with more than 10 people surrounding the surgical bed and a heart-lung machine as big as a tractor!

What an incredible history behind cardiac surgery!

I recently attended a symposium in which I heard several doctors agree to surrender to the hypoplastic left heart syndrome. In my opinion this is, like laying down arms. Do we really want to fight only when we are sure to win?

What would have happened if $\mathrm{W}$. Lillehei had never tried to close a ventricular septal defect with the cross circulation? What if A. Blalock had never tried to use his knowledge to treat tetralogy of Fallot?

It seems that the pediatric cardiac surgery has reached a limit that cannot be overcome. The limit is drawn by the actual capability of having a fetal diagnosis that helps us more and more to avoid the anatomic challenge and not take care of it. One can guess that a severe congenital defect could significantly affect quality of life. This is absolutely true until we are unable to find a solution. Our challenges are the same challenges of the past. Conversely, the society has changed and is asking us to use technologic advances to avoid problems and not to solve them. We should not be part of this mechanism.

I recently had the chance to speak with a pioneer of cardiac surgery. We were speculating about this argument when he told me, "We were inventors and we had fantasy." This phrase seemed like a sentence. And I found it was absolutely true.

For centuries, doctors have tried to improve their knowledge and sought to improve both the duration and the quality of life. We are required to have the same behavior. When facing a small patient suffering from a congenital heart disease, we shouldn't think him as having a "wrong birth" but rather as having inadequate care. This is the essence of medicine.

As a matter of fact, cardiac surgery for acquired disease is still in progress, because for adults there is no other choice than find a solution for complex situations. Modern medicine can't think of pregnancy interruption as the solution for complex congenital heart diseases.

We have to be pioneers; we owe it to the future generations.

Andrea Quarti, MD Department of Paediatric and Congenital Cardiac Surgery and Cardiology Ospedali Riuniti Ancona, Italy

http://dx.doi.org/10.1016/ j.jtcvs.2014.09.086

\section{IS PLEURODESIS FOR THE TREATMENT OF PRIMARY SPONTANEOUS PNEUMOTHORAX A MISNOMER-AND IF IT WORKS, DOES IT MATTER? To the Editor:}

Pleurodesis has been used for more than 60 years to treat the complications of primary spontaneous pneumothorax, persistent or recurrent air leak. It has a commonly quoted success rate of $90 \%$ for this condition.

The term pleurodesis has developed 2 distinct meanings: (1) the instillation of an agent or physical abrasion to cause inflammation in the pleural surfaces and (2) adhesion between the visceral and parietal pleural 